\title{
About Possibilities of Strengthening of Epoxypolymer Composites by Modificated Brick Powder
}

\author{
Dmitro L. Starokadomsky
}

O. O. Chuiko Institute of Surface Chemistry, Kyiv, Ukraine

\begin{abstract}
The composites of the epoxypolymer (EP) with the brick powder (BP) are new materials that combine high characteristics with the low price. Herein we discuss about the several such compositions and evaluate some physical characteristics for them. Presented data suggest that BP (at the concentration range from 5 to $50 \mathrm{wt} \%$ ) increases strength characteristics of the epoxypoly mer's compression and abrasion, and reduce his shrinkiness. At the same time, the BP in 10 wt $\%$ concentration leads to the frustration and defectation in co mposite structure. Under the high concentrations of the BP (50 wt\%) the plastic deformation disappears, the compression strength increases, contraction decreases, and the destruction of template goes through formation of Chernov-Luders Diagonal; but at the same time usage of high concentrations of the BP leads to increase of swelling of the polymer. The obtained results show that particles of brick powder able to significantly strengthen and structurize the EP-composite, at the same time make it more susceptible for liquid corrosion.
\end{abstract}

Keywords Epoxypolymer, Brick Powder, Strength, Compression, Moving, Tearing, Shrinkage, Swelling, Concentr.HNO3, Life-Time, Durability

\section{Introduction}

Due to rising prices on polymeric raw materials, a perspectives of low-cost fillers became actual. In particular, it becomes relevant, if necessary fillers made of materials that pollute the environment (build, industrial and poly mer waste), in relation to new ecologic initiatives in EC and US. One of their materials is brick powder.

Note that the question of hardening epoxy by filling alumina and silica fillers are still relevant, as evidenced the list of works[1-7]. For example, typical filler in studies of new EP-composites stands montmorillonite[3, 8], alumina[10], waste-glass[9]. But in literature data about filling of EP by brick powder have not detected.

The red brick is a product of hard thermo-treatment $\left(>1000{ }^{\circ} \mathrm{C}\right.$ ) of alumosilicates. The brick powder (BP) is a available product and perspective material as recycling filler for poly mers. BP is well compatible with epo xyresins. In this work the character of BP-influence on strength and swelling of epo xy-poly mer (EP). In this work, we avoided the stages of special treatment of BP (organo-modification, ultrasound, endurance in solutions). In the future, we plan to extend the work involving special modifications methods. It is established that decantation in water of thick fraction of

\footnotetext{
* Corresponding author:

stard6@mail.ru (Dmitro L. Starokadomsky)

Published online at http://journal.sapub.org/ajps

Copyright $\left({ }_{0} 2012\right.$ Scientific \& Academic Publishing. All Rights Reserved
}

brick powder let obtain the filler with good compatibility with epoxy-resins. The possiblities of new composite system epoxypolymer - braick powder were invextigated in this work.

\section{Main Body}

\subsection{Experimental Part}

For obtaining of EP-composites, in epoxydian-resin ED-20 (Russian UfaKhimProm production, see formula) added $12.5 \mathrm{wt} \%$ of polyethylene-polyamine. After 5 min of mechanical homogenization, EP-co mposite was hardened at normal conditions during 3 days, after that 100 oC (2 hours) was carried out. For measurements of compression strength (press Louis Shopper), composition was poured in cylindrical forms $(\mathrm{d}=1 \mathrm{~cm})$. From their forms, the cylindrical templates $141.2 \mathrm{~cm}$. The strength to adhesion moving (and tearing) detected on stall plates (and cylinders) adhesive area with glued surface $S=3 \mathrm{~cm}^{2}$ (for tearing $-5 \mathrm{~cm} 2$ ) in machines L.Shopper and Armaveer. Abrasion was determined on the R120 sandpaper with a common passage through $1.5 \mathrm{~m}$. The shrinkage was determined by the change in specimen length of template $\mathrm{h}=1.5 \mathrm{~cm}$ with a micrometer.Swelling measured by growing of mass of templates (lens-form $\mathrm{d}=10 \mathrm{~mm}$, $\mathrm{h}$ (in center) $=2 \mathrm{~mm}$ ) in conc.HNO3 during 15 days. Swell degree $q$ measured as Life-time of template in c.HNO3 evaluated as a time (days) of transition fro solid to viscous (when cannot to VZVESIT) state. 
As filler, the separated (by decantation) brick powder from red usual brick (smooth and dense, production of firm TMM, Ukraine) was used. The decantation carried out by one-stage method: powder poured into a container with distilled water and left for 2 min after shaking poured into a container with distilled water and left after shaking for 2 min.. Then, suspension was separated from sediment, and dried at 100 o C. Surface area of obtained powder was $S \approx 9$ $\mathrm{m} 2 / \mathrm{g}$.

\subsection{Results: Compression Strength}

Diagrams of compression of investigated epoxypoly mer identify their dependence on the concentration and type of BP. As is shown (Figure1), the diagram of destruction at compression for unfilled EP (H-composite) have a well-known[10-12] classic shape. We have two limits (thresholds). The first - the yield stress y1 (tensile strength, the threshold for plastic deformation, plasticity limit) reflect the plastic deformation, when template transform to barrel well-known effect for plastics and metals[10, 11].

For investigated composites, the low dispersion of y1 (2-4\% instead usual $10-15 \%)$ is characteristic.

After reaching the yield point, epoxypolymer sample retains the ability to resist compression for quite some time.

An extended plateau on the diagram after the first threshold corresponds to plastic deformation with an almost constant resistance - "yield plateau"[11]. Note that this can be critical in practically important cases - those which require resistance to the final destruction, and deformation is allowed (in the manufacture of structures, self-leveling floors, furniture). In our case, after y1, tension resistance of the sample is stabilized and then continues to grow (Figure 1) to the second limit (threshold) of strength y2, sometimes referred as "ultimate state", stress of destruction[12], the tensile strength[11, p.23], the limit of tensile strength[12, c.50], the threshold of complete destruction, etc. The destruction of the sample is complete after the second threshold strength y2.

The unfilled polymer is characterized by noticeable fluctuations (serration) of curve deformation-tension, especially at the "yield plateau" $\mathrm{AB}$ between the first and second threshold $\mathrm{y} 1$ and $\mathrm{y} 2$ (Figure 1 , for $\mathrm{C}=0 \mathrm{wt} \%$ ). When you add a $1 \mathrm{wt} \%$ of BP the form of the diagram maintained similar to H-composite, but it smoothed and serration after y1 on "yield plateau" disappears (Figure 1), and "yield plateau" is compressed. At $2 \mathrm{wt} \%$ of the BP type of the diagram is similar to $1 \mathrm{wt} \%$, but significantly different from the diagram for the 0 wt $\%$ (Figure 1): yield area is compressed, and the hardening stage tapers section BC before the final destruction (the limit of destruction and the second threshold strength). At $5 \mathrm{wt} \%$, the "yield plateau" is almost no visible growth of tension is terminated and the final destruction site becomes more clear and sharp (Figure 1). Thus, with $\mathrm{C}>5 \mathrm{wt} \%$ the relative deformation and decrease after the first threshold (yield stress y1) faster the stage of hardening, and tensile strength of y2 (second threshold) increases. This suggests a gradual loss of plasticity and increasing of fragile and hardness with increasing of $\mathrm{C}$, that gives an increase of strength (Table 1 ). Regular change in the form of diagrams and correlation $\mathrm{y} \sim \mathrm{C}$ (hardening with increasing of C) interrupted at $10 \mathrm{wt} \%$. At this concentration, the diagrams of compression back to "imperfect" form, which is typical for the unfilled polymer (Figure 1) - with a gear and a significant yield plateau. This can be considered as an evidence of disordering (loosening, appearance of defects, etc.) of the structure at $\mathrm{C}=10 \mathrm{wt} \%$. At $\mathrm{C}=20 \mathrm{wt} \%$, form of the diagram is similar to the form for 2-5 wt $\%$, although threshold points are poorly visible (Figure 1). This may indicate an improvement of load distribution in the composite (no "failures" and "teeth" on the diagram).

The diagram form changes radically at $\mathrm{C}=50 \mathrm{wt} \%$ (Figure 1). The relative plastic deformation almost stops (no "yield plateau"). And final destruction y2 (the limit of destruction) can be seen by steps gradually (in stages). At $\mathrm{C}=50 \mathrm{wt} \%$ the fracture behaviour of the sample is specific. For $\mathrm{C}=0 \%$ (unfilled polymer) and $1 \leq \mathrm{C} \leq 20 \mathrm{wt} \%$, the destruction of two thresholds (across the barrel-stage and plastic deformation) is completed by cracking along the longitudinal line in a compressed (flattened) sample or dispersal parts of the sample (as in the case of $10 \mathrm{wt} \%$ ). Destruction of the same composite with $50 \mathrm{wt} \%$ of the BP is clearly along the diagonal - to "Chernoff-Luders lines"[13], while its original form does not change. This behaviour sugges ts the formation of a composite with such a high filling of the new reinforced low-plastic structure compared with the lowest content. Perhaps there is a sharp (percolation) changes in the structure at $20<\mathrm{C}<50 \mathrm{wt} \%$.

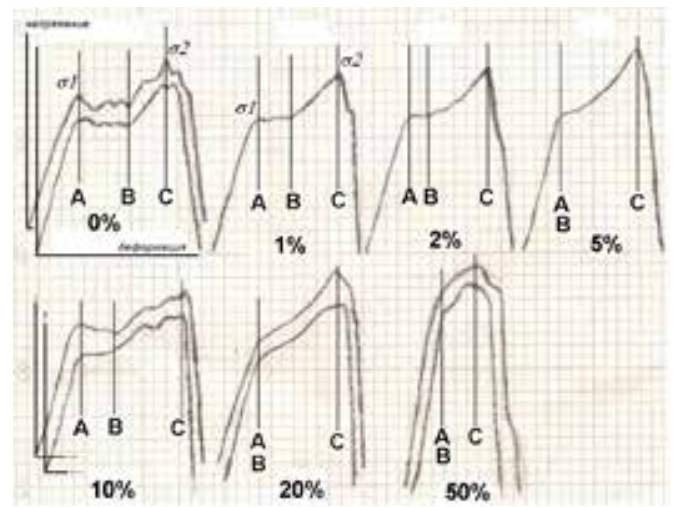

Figure 1. Diagrams of compression of epoxypolymer with $0-50 \%$ by weight of brick powder

It is interesting to consider the changes in the compressive strength of composites with increasing of filling (we accept the parameter $F=y \times 0.7$ ). After filling can increase not only average statistical, but the maximum values of F1 (yield strength), and especially F2 (tensile strength - the final destruction). Thus, for $\mathrm{C}=5,20$ and 50 $\mathrm{wt} \%$, the value of $\mathrm{F} 2 \mathrm{max}$ increases by $10 \%$ compared with $(\mathrm{F} 2 \mathrm{max})_{\mathrm{H}}$ and by $15-20 \%$ compared with averaged $\mathrm{F} 2 \mathrm{H}$ for unfilled polymer. This fact shows an essential reserve of composite strengthening by optimization the concentration 
and the production technology of the composite. Note that the scatter of values (a difference of Fmax - Fmin) is very significant for the 0 and $10 \mathrm{wt} \%$, to a lesser extent - for 5 and $20 \mathrm{wt} \%$, but the minimum for $\mathrm{C}=1,2$ and $50 \mathrm{wt} \%$. This may indicate completion of the optimum composite structuring under the effect of low and very high concentrations of BP, and confirms the assumption that the growth defect of the structure after $5 \%$ by mass and particularly in the vicinity of $10 \%$ of the mass of filling the BP. From Figure 3 it can be concluded that the most resistant to fracture under compression of the composite structure is formed around of $5 \mathrm{wt} \%, 20 \mathrm{wt} \%$ and especially $50 \mathrm{wt} \%$.

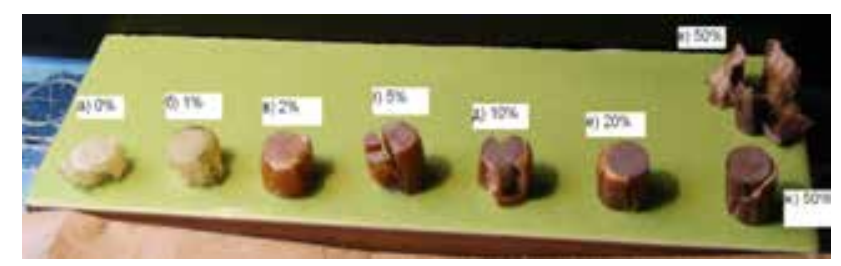

Figure 2. Compression failure types of the composite samples from 0 50 wt \% of BP. Table 1. Compression strength for the first F1 (plastic deformation) and the second F2 (final failure) threshold destruction of epoxypolymer, depending on BP-content

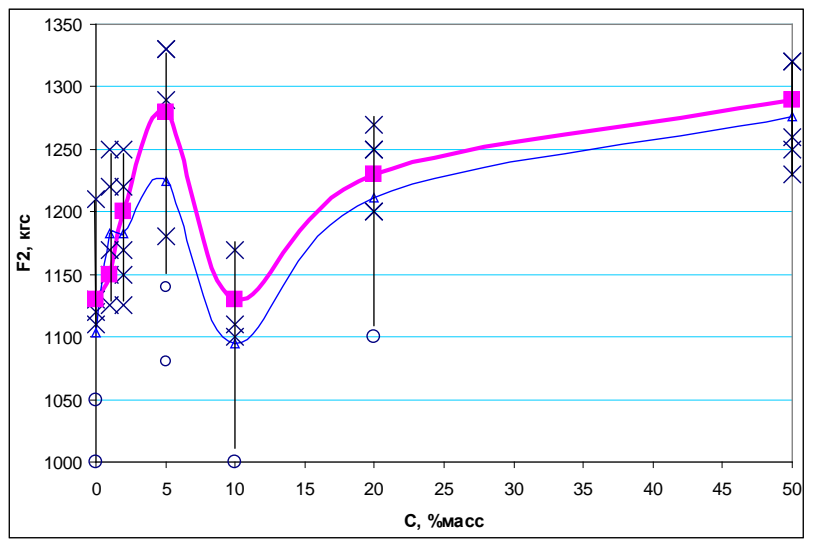

Figure 3. The dependence of the efforts for the second threshold F2 of compressive strength (in kgfto $0.7 \mathrm{~cm} 2$ of area) on the concentration of BP. Thick curve is averaging curve without the lowest values (only on cross-points, without marked by circles), thin - the curve of general average (of all points)

Strength of the composite curve of the concentration of BP in the resin is characterized by extremumes. The introduction of small a mounts of BP almost does not increase the strength of the composite $\mathrm{F}$ that distinguishes BP from aerosil-type nanosilicas. So, at $\mathrm{C}=1 \mathrm{wt} \% \mathrm{~F} 1 \approx \mathrm{F} 1 \mathrm{H}$ and $\mathrm{F} 2$ grows only on $2-3 \%$; at $\mathrm{C}=2 \mathrm{wt} \% \mathrm{~F} 1 \approx \mathrm{F} 1 \mathrm{H}$ and $\mathrm{F} 2$ grows more noticeable (6\%). Thus, for the $1-2 \mathrm{wt} \%$, significant changes in the values of F1 (limit of plasticity) is not observed, and weak strengthening of F2 (the limit of destruction) takes place.

The same subtle influence of small amount of BP is observed for resistance to abrasion and shrinkage (see below, tab.2). Thus, despite the significant visual change in the composite (darkening Figure 2), no significant changes (deteriorating) in the strength characteristics of the composite, which can be used, for example, as decorative compositions). This can be called a significant difference BP
- microfiller from nanofillers (eg Aerosil), which gives a noticeable mechanical effect at low concentrations.

Increasing concentrations of $\mathrm{BP}$ up to $5 \mathrm{wt} \%$ gives obvious signs of composite hardening, especially $\mathrm{F} 2>>\mathrm{F}_{2} \mathrm{H}$ (Table 1). It means non-randomness, hardly noticeable increases in the strength characteristics for the resin filled by small a mount of a lu mina.

At $10 \mathrm{wt} \%$ character of destruction at compression changes and parameters of F1 and F2 falls to the level of $\mathrm{H}$-composite. In this case because of the composite fragility it was difficult to fix the exact values of F2: every third test, the sample is not formed a barrel (as at other concentrations $\mathrm{BP}$ ), and fly to pieces after the pass the first strength threshold F1. In some cases, filling with $10 \mathrm{wt} \% \mathrm{BP}$ significantly increases the instability of instrument reading ("pointer jumping") when tested in compression, which is characteristic of the composite with highly-defective structure. Note that in research of composites "EP-nanosilica" the "loosening filler concentrations" also were found, when the strength parameters were decreased to a minimum (3 and $7 \mathrm{wt} \%$ of silica A-100) due to embrittlement of the polymer[6, 9]. However, this is not evidence of the fall of all strength parameters. For example, when $\mathrm{C}=10 \mathrm{wt} \%$ were increased abrasion resistance (an increase of 15-20\%) and the strength of adhesive tearing $\Theta$ (an increase in 1.5 times) compared with rates for $\mathrm{H}$-composite (tab.2). Note that if compare $5 \mathrm{wt} \%$ to $10 \mathrm{wt} \%$ was no increase of swelling in a solution of HNO3 (see below), i.e. embrittlement and estimated growth of the defect structure is not accompanied by changes in permeability (density) of polymer network.

In case of $\mathrm{C}_{\mathrm{BP}} \geq 20 \mathrm{wt} \%$, the new increase in compressive strength observes (growth rates F1 and F2, Table 1). Figure 2 shows that the character of destruction is changed in comparison with 5-10 wt\% content - it is similar to destruction for low-filled composites (1-2 wt\%). For C= 20 wt $\%$, a small dispersion of the data - 2-3\% (it is typical for $1<\mathrm{C}<2 \mathrm{wt} \%$ ) observes. This suggests that at $20 \%$ by weight of the composite structure is optimized by eliminating or compensating for the typical for $10 \%$ of the mass defect of provoking increased fragility and instability properties.

With increasing of BP content up to $50 \mathrm{wt} \%$, the tendency toward hardening of the composite reinforced (Table 1). The nature of fracture under compression changes significantly it becomes a non-plastics. As you can see from Figure1, it is almost impossible to distinguish the first threshold F1 (the yield stress or plasticity) with such content, as a straight section of the curve 0 -A of destruction extended (section AB disappears) and extended almost to the limit of final destruction F2 (i.e. section BC is greatly reduced, Figure1). But rough estimates of the values of F1 (point A on the curve for the $50 \mathrm{wt} \%$, Figure 1 ) suggest a very significant increase in their (up to $18-24 \%$ ) compared to F1 to $\mathrm{H}$. There is also the maximum growth of value F2 - over 14\% (Table 1). Obviously, there is essential change in the structure of the composite, causing percolation phenomena while transition from $\mathrm{C}=20$ to $\mathrm{C}=50 \mathrm{wt} \%$. 
Table 1. Compression strength for the first F1 (plastic deformation) and the second F2 (final failure)threshold destruction of epoxypolymer, depending on BP-content

\begin{tabular}{|c|c|c|c|c|c|}
\hline \multirow[b]{2}{*}{ Sample, wt $\%$ of BP } & \multicolumn{5}{|c|}{$\begin{array}{l}\text { The values of the breaking load, kgf for the first and second thresholds compressive strength - F1 - F2 } \\
\qquad(\mathrm{F}=\mathrm{y} \times 0.7, \mathrm{MPa}) .\end{array}$} \\
\hline & Averaged & Д+-\% & $\begin{array}{l}\text { In } \% \\
\text { to } \mathrm{FH}\end{array}$ & The maximum & In $\%$ to $($ Fmax $) H$ \\
\hline 0 (H-composite) & $95-113$ & $5-7$ & $100-100$ & $99 *-121$ & $100-100$ \\
\hline $1(\mathrm{~K} 1)$ & $95-115$ & $2-3$ & $100-102$ & 95-115 & $96-95$ \\
\hline $2(\mathrm{~K} 2)$ & $94-120$ & $0-3$ & 99-106 & $94-125$ & $95-103$ \\
\hline $5(\mathrm{~K} 5)$ & $97,5-128$ & $3-7$ & $103-113,5$ & $102-133$ & $103-110$ \\
\hline $10(\mathrm{~K} 10)$ & $93,5-113$ & $4-4$ & $98-100$ & $97-117$ & $98-97$ \\
\hline $20(\mathrm{~K} 20)$ & $100-123$ & $2-3$ & $105-109$ & $100-127$ & $101-105$ \\
\hline $50(\mathrm{~K} 50)$ & $115-129$ & $2-3$ & $121-114$ & $120 *-132$ & $121-110$ \\
\hline
\end{tabular}

* - The value of F1 is approximate

Table 2. Abrasion, adhesion strengh to a shift in the separation and shrinkage of epoxy composites, depending on the cont ent of the BP

\begin{tabular}{|c|c|c|c|c|c|c|c|c|}
\hline & & \multicolumn{7}{|c|}{ BP, wt \% } \\
\hline & $\Delta+-$ & 0 & 1 & 2 & 5 & 10 & 20 & 50 \\
\hline Abrasion D, mg & 2 & 32 & & 32 & & 27 & 27 & 23 \\
\hline Separation $\Theta \times 5, \mathrm{MPa}$ & 5 & 40 & 40 & & 30 & 60 & & \\
\hline Shift $\tau \times 3, \mathrm{MPa}$ & 0,7 & 15 & & 13,5 & & & & 15 \\
\hline Shrinkage, mm & 0,2 & 4 & 4 & 4 & 3,5 & 3,5 & 2 & 0,1 \\
\hline
\end{tabular}

\subsection{Other Characteristics of the Composites}

Other mechanical characteristics also serve as indicators of structural change with the introduction of brick powder. Data on the shrinkage of the composites show a significant decrease only at high contents of BP. As can be seen from tab. 2 at $\mathrm{C}<=20 \mathrm{wt} \%$ change of shrinkage is insignificant (about 10\% compared with H-composite, tab.2). Ho wever, at $20 \mathrm{wt} \%$ is observed double reduction of shrinkage, and at 50 wt $\%$, it almost does not occur (in 40 times less than for H-composite, tab.2). This confirms the conclusion of the hardening of the co mposite structure the high contents of BP.

Abrasion D (wear resistance) of composites does not change up to $\mathrm{C}=10 \mathrm{wt} \%$. At $10<\mathrm{C}<20$ wt $\%$ abrasion resistance is essential enhanced ( $D<D_{H}$ by $15-20 \%$, tab.2). This may be due to the emergence of a appearance of own $\mathrm{Al}_{2} \mathrm{O}_{3}-\mathrm{SiO}_{2}$-structures in the polymer, which themselves have abrasive properties. This assumption is supported by a noticeable increase in wear resistance at a concentration of $50 \mathrm{wt} \%$ of the BP, when the wear is reduced by $40 \%$ compared with the $\mathrm{H}$ (tab.2). From tab.2 can see that by varying of $\mathrm{C}_{\mathrm{BP}}$ can to increase the strength to adhesion separation (if $\mathrm{C}=10 \mathrm{wt} \%$, tab.2).

\subsection{Effect of BP Filling on the S welling of Polyepoxi des}

In the same time, filling changes (weaken) the resistance to decrease swelling in aggressive solutions, for example, in $20 \%$ HNO3. For low-filled composites ( $\mathrm{C}_{\mathrm{BP}}=1-2 \mathrm{wt} \%$ ) increase in swelling is not always apparent, for highly-filled influence of alu mina becomes significant. The weakening of the composite resistance to swelling at high contents of BP may be explained by high-permeability (channel, porous, etc.) structure in the polymer.

$\mathrm{T}$ In earlier our work was showed that a stage of quasi-saturation of polyepoxides swelling in dilute nitric acid[9] is possible. As you can see in 20\% HNO3 (Figure4), for unfilled polyepoxide (H-composite) and for $\mathrm{C}=1 \mathrm{wt} \%$ quasi-saturation is observed for 20-35 and 5-20 days of exposure; then begins a new stage of activation of swelling. For $\mathrm{H}$, the swelling can be considered relatively small $-2.5 \%$ after 1 month, 4\% after 2 months (Figure4).

Filling by $\mathrm{C}>1 \mathrm{wt} \%$ leads to the disappearance of quasi-saturation site. In most cases, swelling curve can be divided into the initial stage of swelling area at high speed (up to 20 days), and subsequent swelling of the stage, where the rate is reduced (after which the effective rate of swelling decreases, Figure 4). For example, for $\mathrm{C}=50 \mathrm{wt} \%$ first stage of swelling (up to 20 days) is characterized by the rate of $\mathrm{V}=$ $4 \%$ day, while the second V = 1,5\%/day (Figure4).

Usually there is a clear regularity - with increasing of $\mathrm{C}$ the degree of swelling increases (Figure4, Figure5). For $\mathrm{C}=1$ $w t \%$, the nature of the swelling does not change: the curve "q-time" copies the curve for H-composite (Figure 4). However, at $\mathrm{C}=2 \mathrm{wt} \%$ and $5 \mathrm{wt} \%$, there is intensification of swelling at all stages of aging.

For $\mathrm{C}=10 \mathrm{wt} \%$ the degree of swelling may sometimes decrease compared to $5 \%$ by mass (for example, with 7 days 
exposure, Figure 5). This suggests that the structure of the composite at 5 and $10 \mathrm{wt} \%$ is about the same, which is expressed in the same permeability to mo lecules of the liquid medium. However, this conclusion seems surprising, given the dramatic differences in compressive strength (tab. 1, Figure 3) and separation (tab.2). We can suggest that in the range $5 \mathrm{wt} \%$ a strong set, but more permeable to the solvent structure of the composite (relative to unfilled polymer). Most likely, a major role in structuring the composite play alu minosilicate framework structures. Thus, with increasing of filling of $\mathrm{C}=5$ or $10 \mathrm{wt} \%$, the density of the structure remains unchanged, but increases its imperfection and fragility, which leads to a drop in strength while maintaining resistance to swelling (compared to $5 \mathrm{wt} \%$ ).

The noticeable intensification of swelling occur for $\mathrm{C}_{\mathrm{BP}}=20 \mathrm{wt} \%$ and especially $50 \mathrm{wt} \%$ (Figure4, Figure5). At $20 \mathrm{wt} \%$, the swelling increased very significantly $(\mathrm{q}(20 \mathrm{wt} \%) / \mathrm{q}(\mathrm{H}) \approx 3, \mathrm{q}(20 \mathrm{wt} \%) / \mathrm{q}(5$ or $10 \mathrm{wt} \%) \approx 2)$. This suggests a significant loosening of the structure of composite from $C=10$ to $C=20 \mathrm{wt} \%$, which is typical for nanosilica[9]. Trends to increase swelling with increasing of filling continues from 20 to $50 \mathrm{wt} \%$. For $\mathrm{C}=50 \mathrm{wt} \%$ can see the visual differences: the composite is similar to cast stone, but when exposed to a solution of HNO3, its quickly brightens. The growth of strength at 20 and especially $50 \mathrm{wt} \%$ shows a high-permeability formation for liquids, but resistant to the stresses of the composite frame structure.

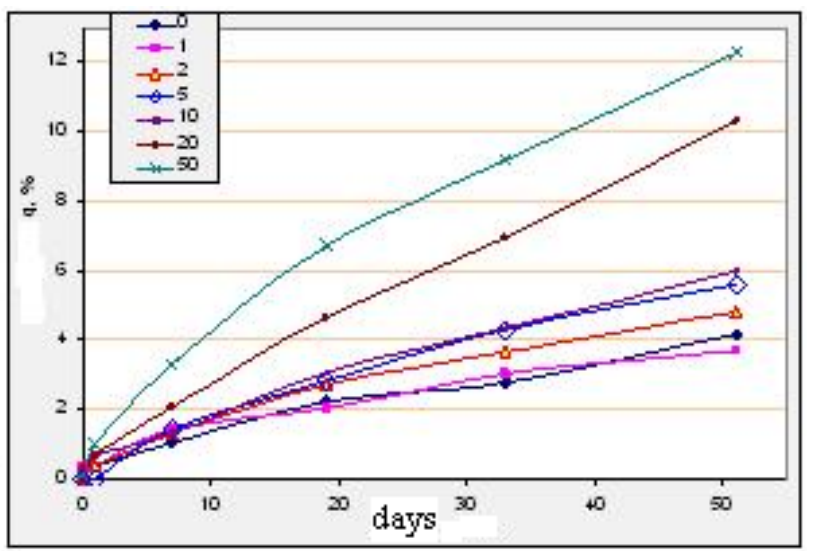

Figure 4. The swelling curves of $\mathrm{PE}$ with $0-50 \mathrm{wt} \%$ of $\mathrm{BP}$ in $20 \% \mathrm{HNO}_{3}$

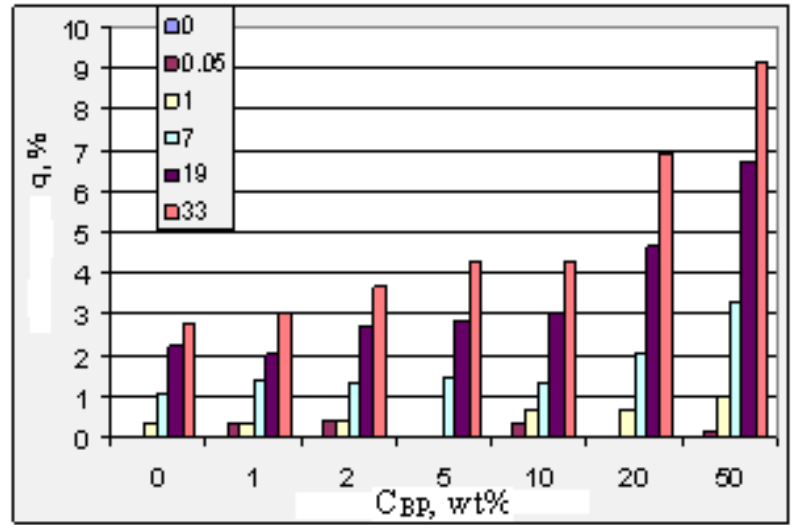

Figure 5. Changes in the degree of swelling of PE with 0-50 wt\% of BP as a function of exposure time in $20 \% \mathrm{HNO}_{3}$

\section{Conclusions}

The introduction of BP in a wide concentration range (1-50 wt\%) can be an effective method to control the strength, shrinkage and durability/swelling of epoxypolymer composite.

Each concentration of BP-filler is characterized by own structure of compression diagram. The introduction of BP generally has a reinforcing, structuring effect on the epoxypolymer. Also established the possibility of the existence of not only optimal, but suboptimal concentrations of BP (10 wt\%) composites, in which the inherent instability and loss of original strength properties takes place.

It is shown that low concentrations of BP (1-2 wt\%) have weak effect on compressive strength, abrasive, swelling and shrinkage of the composite. The introduction of BP in large quantities can prevent shrinkage of the composites, and in this case - to increase the compressive strength and abrasion resistance of composites. In this case, however, starting with $\mathrm{C}_{\mathrm{BP}}=2 \mathrm{wt} \%$ resistance of the composite to an aggressive (acidic) environment is reduced. This is reflected in the growth of the swelling in the nitric acid of filling is increased, especially after $\mathrm{C}_{\mathrm{BP}}=10 \mathrm{wt} \%$.

The effect of significant changes in the properties of the composite (percolation threshold) in $\mathrm{C}_{\mathrm{BP}}=50 \%$, which influences in a change in the form of diagrams, the nature of fracture, and a sharp rise in the compressive strength, abrasion, swelling and reducing shrinkage.

\section{REFERENCES}

[1] M.Worzakovska. "Epoxy matrix composites filled with glass wastes.”, in Proceedings of Intern.Conf. “Actual Problems of Surface Chemistry”, Kiev, Ukraine, 2010.

[2] V.L. Demchenko, V. I. Shtompel, V.O. Vilensky, "Features of the structure of composites based on polymer mesh structure and oxides of Fe (III) and Al (III), formed in a constant electric fielid”, Polymer Journal (in Russian), V.31, № 3, pp.235-243, 2009.

[3] Y.Y.Choi, S.H.Lee, S.H.Ryu, "Effect of silane functionalization of montmorillonite on epoxy/montmorillonite nanocomposite”, Polymer Bulletin, N 63, pp.47-55, 2009.

[4] "Polymer/layered silicate nanocomposites by combined intercalative polymerisation and melt intercalation: a masterbatch process", B.Lepoittevina, N.Pantoustiera, M.Devaickenaerea, M.Alexandrea, C.Callergb, R.Jeromeb, C.Henristd, A.Rulmond, Ph.Dubois, POLYMER, V.44, N7, pp.2033-2040, 2003.

[5] I.G. Dobrotvor, P.D. Stuhlyak, A.V. Buketov, "Determination of optimal ranges of dispersed filler content in epoxypolymer composition”, Phys.-Chim.Mehanika Materials (Riga, EC), № 6, ppp.32-39, 2009.

[6] D.L. Starokadomsky, "The effect of the content of the unmodified nanodispersed silica with different specific surface on the mechanical properties of epoxypolymer 
composites”, Journal of Applied Chemistry, № 12, pp.2045-2051, 2008.

[7] V.A. Liopo, V.A. Struk, S. Avdeychik, "The mechanism of the doping nanoscale modifiers in the polymer matrix", Plastics, 2007, № 8, pp...36-39.

[8] V.A. Borisov, Y.U. Bedanokov, A.M. Karmok, A.K. Mikitaev, M.A. Mikitaev, E.R. Turaev, "Properties of polymer nanocomposites based on organo-modified $\mathrm{Na}$ +-montmorillonite”, Plastics, 2007, № 7, pp.30-32.

[9] D.L. Starokadomsky, "The concentration and dispersity of aerosil as a factor of change in chemical resistance and durability of epoxy-based DE-20 + PEPA", Proceedings Slavpolykom 2008, Kiev-Yalta, 2008, pp.40-44.
[10] Epoxy or polyepoxide containing coating...Composition comprising thermosetting plastic resin with comminuted recycled glass powder as a filler. // Patents In Field 427/386 patents.justia.com/field/427-386.html.

[11] M.M.Fylonenko-Borodin, S.M. Yzyumov, B.A. Olysov, I. N. Kudryavtsev, L.I. Malginov, "Course of resistance of materials”, Moscow: USSR-HYTTL, 1956, 650 p.

[12] NK Snytko, "Resistance of materials”, Leningrad: Edition LHU, 1975, 370 p.

[13] Introduction to resistance of materials. Ed. VE Melnikov, St.Petersburg (Russia), 1999, $160 \mathrm{p}$.

[14] Stepin PA, “Resistance of materials”, Moscow, 1998, 320 p 